\title{
THE EFFECTS OF HYDROGEN, TRITIUM, AND HEAT TREATMENT ON THE DEFORMATION AND FRACTURE TOUGHNESS PROPERTIES OF STAINLESS STEEL
}

\author{
M.J. MORGAN, M. H. TOSTEN, AND G.K. CHAPMAN \\ Savannah River National Laboratory, USA \\ Savannah River Site \\ Aiken, SC 29808
}

\begin{abstract}
The deformation and fracture toughness properties of forged stainless steels pre-charged with tritium were compared to the deformation and fracture toughness properties of the same steels heat treated at $773 \mathrm{~K}$ or $873 \mathrm{~K}$ and precharged with hydrogen. Forged stainless steels pre-charged with tritium exhibit an aging effect: Fracture toughness values decrease with aging time after precharging because of the increase in concentration of helium from tritium decay. This study shows that forged stainless steels given a prior heat treatment and then pre-charged with hydrogen also exhibit an aging effect: Fracture toughness values decrease with increasing time at temperature. A microstructural analysis showed that the fracture toughness reduction in the heat-treated steels was due to patches of recrystallized grains that form within the forged matrix during the heat treatment. The combination of hydrogen and the patches of recrystallized grains resulted in more deformation twinning. Heavy deformation twinning on multiple slip planes was typical for the hydrogen-charged samples; whereas, in the non-charged samples, less twinning was observed and was generally limited to one slip plane. Similar effects occur in tritium pre-charged steels, but the deformation twinning is brought on by the hardening associated with decay helium bubbles in the microstructure.
\end{abstract}

\section{INTRODUCTION}

Tritium gas is processed and stored at the Savannah River Site in stainless steel vessels. Austenitic stainless steels are highly compatible with tritium but, after long term use, tritium and its decay helium reduce fracture toughness and can induce subcritical crack growth. The fracture toughness reduction over time is an aging effect and a form of hydrogen embrittlement that is made worse by 
the effects of decay helium on the deformation properties of the material [1-3]. There is widespread interest in the effects of hydrogen, tritium, decay helium, and irradiation on the structural properties of these materials [4-9].

In this study, it is shown that forged stainless steels that are heat treated can also exhibit an aging effect after they are precharged with hydrogen: Fracture toughness values decrease with increasing time at temperature in the sensitization temperature range, 773-873 K.

Are the deformation and fracture mechanisms caused by tritium and decay helium similar to those caused by hydrogen observed in heat-treated steels? In this study, the deformation and fracture toughness properties of heat treated stainless steels pre-charged with hydrogen were investigated and compared to prior investigations on the deformation and fracture toughness values of the same stainless steels pre-charged with tritium.

\section{EXPERIMENTAL PROCEDURE}

Arc-shaped fracture toughness samples (Fig. 1) were fabricated from Type 21-6-9 forged stainless steels and fatigue pre-cracked. The compositions of the steels are listed in Table 1. The steels were in the form of forward extruded cylindrical conventional (CF) or high-energy-rate forgings (HERF) and were from the same heats and forgings of earlier studies [1]. Samples were heat treated at $773 \mathrm{~K}$ or $873 \mathrm{~K}$ for times up to 24 hours. After heat treatment about one-half of the samples were pre-charged with hydrogen gas at $34 \mathrm{MPa}$ and 623 $\mathrm{K}$ for 2 weeks. The temperature of exposure was chosen so as to uniformly saturate the samples with hydrogen or tritium while minimizing any further change in the steel microstructure. Fracture toughness testing was conducted on the uncharged and pre-charged samples. The results were compared to earlier studies done on the same steels pre-charged with tritium (using the same conditions ) but not given a prior heat treatment.

After the specimens were heat treated and / or precharged, J-Integral tests were conducted at room temperature in air using a screw-driven testing machine and a crosshead speed of $0.002 \mathrm{~mm} / \mathrm{s}$ (J-Integral rate $\sim 0.45 \mathrm{~kJ}-\mathrm{sq} \cdot \mathrm{m}^{-1} / \mathrm{s}$ ) while recording load, load-line displacement with a gage clipped to the crack mouth, and crack length. Crack length was monitored using an alternating DC potential drop system. The J-Integral versus crack length increase (J-R) curves were constructed from the data using ASTM E 1820-99 and the fracture toughness value, $\mathrm{J}_{\mathrm{Q}}$, was determined from the intercept of the $\mathrm{J}$ $\mathrm{R}$ curve with the $0.2 \mathrm{~mm}$ offset line [10].

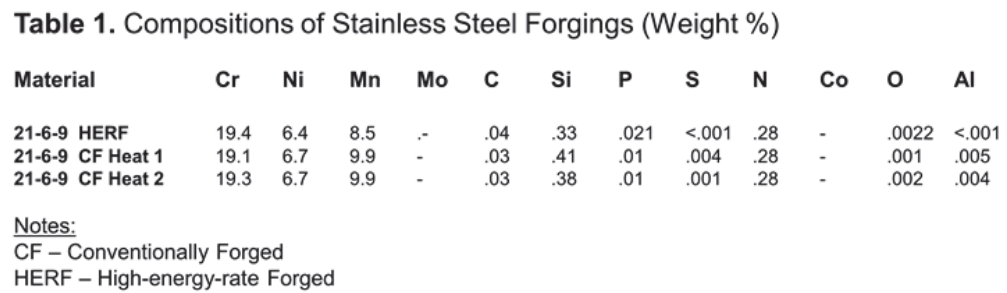




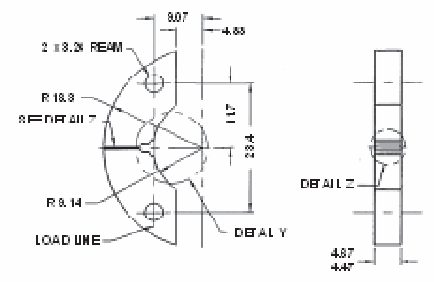

Figure 1. Shape and dimensions of fracture-toughness sample. Dimensions shown are in millimeters.

\section{RESULTS}

The fracture toughness test results for the heat treated samples are summarized in Figure 2. Notice that the fracture toughness measurements for the uncharged specimens heat treated at $773 \mathrm{~K}$ remained relatively constant for heat treatment times up to 24 hours. This result is consistent with a microstructural analysis of the $773 \mathrm{~K}$ specimens in which no differences were observed in grain structure or carbide distribution throughout the range of heat treatment times (see below). Figure 2 also shows that hydrogen-charged specimens (Heat 1) which were heat treated at 773 showed a general reduction in fracture toughness of about $30 \%$ at all heat treatment times when compared to the uncharged samples - a typical reduction in toughness for hydrogen-saturated Type 21-6-9. There was no additional effect of heat treatment time on fracture toughness properties at this temperature. Figure 2 also shows that hydrogen-charged samples heat treated at $873 \mathrm{~K}$ had initial fracture toughness values (after 10 and $60 \mathrm{~min}$.) similar to the $773 \mathrm{~K}$ samples. At the longer heat treatment times the toughness dropped off to about $50 \%$ of the initial values.

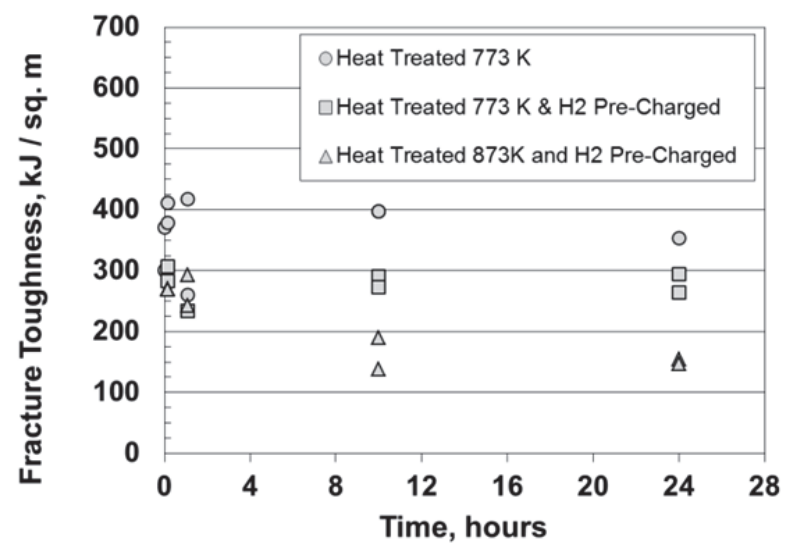

Figure 2. Hydrogen Precharged Stainless Steels (Heat 1) Exhibit a Reduction in Fracture Toughness Properties after a Prior Heat Treatment. 
A microstructural analysis of foils from near the fracture surface of the heat treated steels was conducted in order to elucidate microstructural changes that could be related to the fracture toughness reductions caused by heat treatment and hydrogen of Fig. 2. No differences in grain structure or carbide distribution were evidenced throughout the range of heat treatment times for the $773 \mathrm{~K}$ heat treatment. However, Fig. 3 shows that there were changes to the microstructure after the $873 \mathrm{~K}$ heat treatments. While grain boundary carbide formation was not detected, patches of recrystallized grains formed in the forged matrix. The microstructures of selected samples are shown in the optical and scanning electron micrographs of Figure 3. The optical micrograph in Fig. 3(a) shows that, typically, the as-forged steels had elongated grains deformed in the direction of forging. Heat treatments at $773 \mathrm{~K}$ had no discernible effect on the microstructure. The scanning electron micrographs in Figs 3 (b) \& (c) show that heat treatments at $873 \mathrm{~K}$ resulted in the formation of small, recrystallized on the boundaries of the elongated grains. Was this the cause of deleterious effect of hydrogen on toughness observed in the $873 \mathrm{~K}$ samples of Fig. 2?
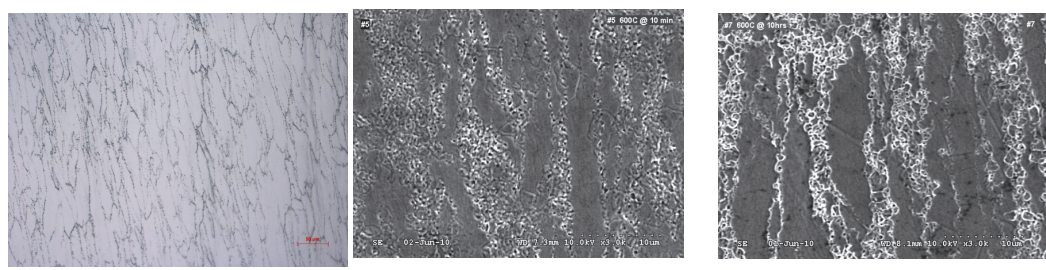

Figure 3. Microstructures of (a) As Forged Steel (optical image); (b) Heat-Treated for 10 Min. at $873 \mathrm{~K}$ (Scanning Electron Microscope Image); and (c) Heat Treated for 10 Hours at $873 \mathrm{~K}$ (SEM Image).

Transmission electron microscopy (TEM) was conducted on foils prepared from immediately beneath the fracture surfaces and from the bulk material. First of all, TEM analysis indicated that carbide formation in this material was very limited. Even in material heat treated at $873 \mathrm{~K}$ for $10 \mathrm{hr}$. carbides were rarely observed. Based on the results of these observations, the reduction in toughness of Fig. 2 was not caused by a combination of hydrogen and carbide precipitation.

On the other hand, Fig. 4a shows the microstructure of a sample heat treated for $10 \mathrm{hr}$. at $873 \mathrm{~K}$ and $\sim 2 \mathrm{~mm}$ from the fracture surface. Typical of all specimens, patches of recrystallized grains have formed in an unrecrystallized "matrix". Fig. 4b shows the microstructure about $0.75 \mathrm{~mm}$ from the fracture surface from a sample containing hydrogen and heat treated at $773 \mathrm{~K}$ for $10 \mathrm{~min}$. In this image two different variants of deformation twins have formed in an unrecrystallized grain. Heavy deformation twinning on multiple slip planes was typical for the hydrogen-charged samples whereas in the uncharged samples less twinning was observed and was generally limited to one slip plane. Furthermore, deformation (via twinning) was not concentrated in the recrystallized grains as expected. In fact twinning was more prevalent in the unrecrystallized grains in those TEM specimens examined. 

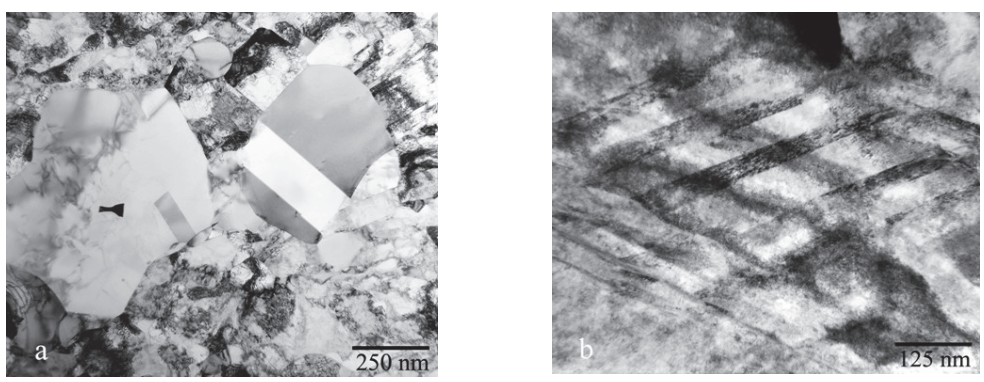

Figure 4. TEM images of Type 21-6-9, a) recrystallized grains in a deformed matrix b) deformation twinning in a hydrogen-charged specimen.

These microstructural observations suggest that toughness decreased for the hydrogen-charged samples heated at $873 \mathrm{~K}$ because of the formation of recrystallized grains. The patches of recrystallized grains will occupy more volume as heat treatment time or temperature increases and deformation by twinning will be concentrated in the remaining volume of material that is unrecrystallized. The concentrated deformation would result in smaller microvoids on the fracture surface because of enhanced shear fracture.

An enhanced shear fracture mechanism is consistent with the fracture appearance of these samples, shown in Fig. 5. First of all, hydrogen-charged samples had smaller microvoids on the fracture surface than did the as-received or as-heat-treated samples. Furthermore, while heat treatment alone tended to change the fracture appearance, Fig. 5a, it did not change fracture toughness very much unless hydrogen was also present (Fig. 2). When hydrogen is present, and deformation by twinning more concentrated, the fracture appearance was characterized by even small microvoids (Fig. 5b,c).

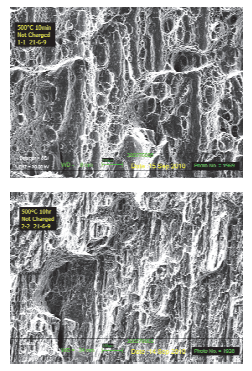

773 K-Not Charged
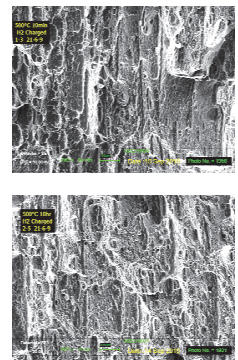

773K, H2-Charged
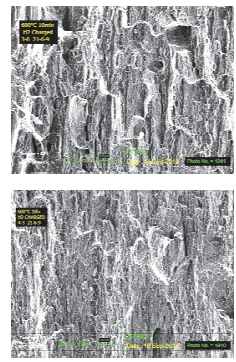

$873 \mathrm{~K}, \mathrm{H} 2-$ Charged
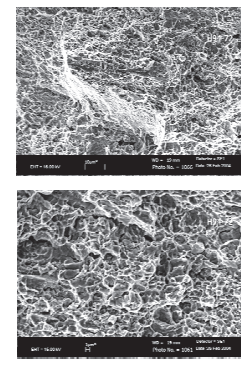

Tritium-Charged,

250 appm He

Figure 5. Fracture Appearance of Samples: (a) 773 K 10 min and 10 hours, Not-Charged; (b) $773 \mathrm{~K}$ $10 \mathrm{~min}$ and 10 hours, Hydrogen-Charged; (c) $873 \mathrm{~K} 10 \mathrm{~min}$ and 10 hours, Hydrogen-Charged; and (d) Tritium-Charged-and-Aged, 250 appm Helium from Tritium Decay. 


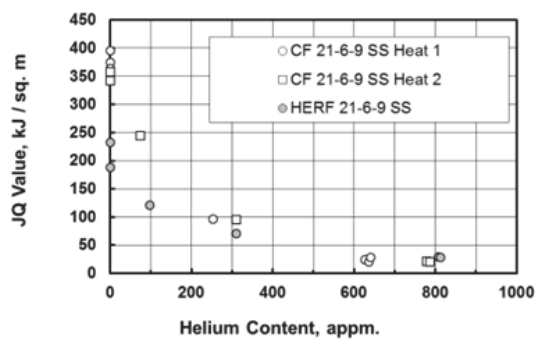

(a)

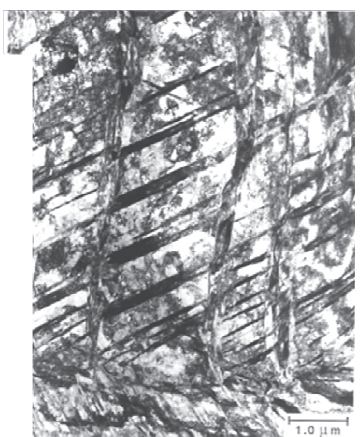

(b)

Figure 6. (a) Fracture Toughness Reductions After Tritium Precharging Occur Over Time Due to the Build-in of Helium From Tritium Decay. (b) Helium Bubbles From Tritium Decay Harden the Microstructure and Promote Deformation by Twinning [1-2].

The deformation and fracture mechanisms observed in these heat-treated steels are similar to those in tritium-charged-and-aged steels, shown in Fig. 6 [13]. Helium bubbles from tritium decay pin dislocations and create obstacles to dislocation motion within the microstructure. The hardened steel plastically deforms by twinning which, in combination with tritium, results in easier crack nucleation [2].

Finally, the results of this study suggest that it may be possible to use heat treatments of forged stainless steels to probe the potential of a particular forging or heat of steel to tritium embrittlement. Figure 7 shows that, in this study, hydrogen-charged samples given a prior heat treatment of $873 \mathrm{~K}$ up to 24 hours had fracture toughness reductions and fracture modes (Fig. 5c\&d) that were remarkably similar to the toughness reductions observed in similar heats of steel that required more than seven years of aging to build-in the helium from tritium decay. This will continue to be explored in future work. 
Heat Treatment Time at $600 \mathrm{C}$, hours

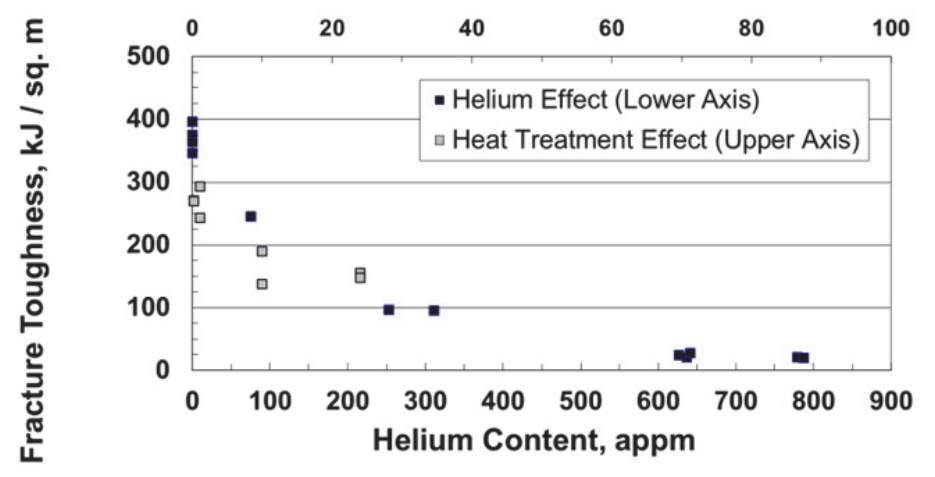

Figure 7. Hydrogen-Precharged Steels Given a Prior Heat Treatment at $873 \mathrm{~K}$ Show Similar Fracture Toughness Reductions As Tritium-Precharged Samples.

\section{CONCLUSIONS}

1. Forged stainless steels pre-charged with tritium gas exhibit an aging effect: Fracture toughness values decrease with aging time due to an increasing concentration of helium-3 within the microstructure from tritium decay.

2. Forged stainless steels that are given a prior heat treatment in the temperature range $773-873 \mathrm{~K}$ and then precharged with hydrogen also exhibit an aging effect: Fracture toughness values decrease with increasing temperature and heat treatment time.

3. For steels heat treated at $773 \mathrm{~K}$, hydrogen caused a $30 \%$ reduction in the fracture toughness value. Similar hydrogen-induced reductions were observed in non-heat treated steels. For steels heat treated above $773 \mathrm{~K}$, hydrogen caused fracture toughness values to decrease to about $50 \%$ of their initial value as heat treatment time increased.

4. The fracture toughness reduction observed in heat-treated steels at longer aging times was caused by an increase in the number of recrystallized grains in the forged matrix. The increased number of recrystallized grains enhanced the deleterious effect of hydrogen on toughness by increasing the amount of deformation twinning.

5. The fracture and deformation mechanisms caused by hydrogen in heattreated steels appear to be similar to the fracture and deformation mechanisms observed for steels precharged with tritium. 


\section{ACKNOWLEDGEMENTS}

This manuscript has been authored by Savannah River Nuclear Solutions, LC under Contract No. DEAC09-08SR22470 with the U.S. Department of Energy. The United States Government retains and the publisher, by accepting this article for publication, acknowledges that the United States Government retains a non-exclusive, paid-up, irrevocable, worldwide license to publish or reproduce the published form of this work, or allow others to do so, for United States Government purposes.

\section{REFERENCES}

[1] Morgan, M.J. and Tosten, M.H., 1996, "Tritium and Decay Helium Effects on the Fracture Toughness Properties of Types 316L, 304L, and 21Cr-6Ni-9Mn Stainless Steels," Hydrogen Effects in Materials, A. W. Thompson and N. R. Moody, eds., (Warrendale, PA: TMS), p. 873.

[2] Morgan, M.J., West, S.L., Tosten, M.H., 2008, "Effect of Tritium and Decay Helium on the Fracture Toughness Properties of Stainless Steel Weldments", Fusion Science and Technology, 54, No. 2, pp. 501-505.

[3] Robinson, S.L., 1989, "The Effects of Tritium on The Flow and Fracture of Austenitic Stainless Steels," Proc. Fourth Int. Conf. on Hydrogen Effects on Material Behavior, A. W. Thompson and N. R. Moody, eds., (Warrendale, PA: TMS), p. 433.

[4] Abramov, E., Moreno, D., Solovioff, G., Eliezer, D., 1994, "Surface Behavior of First-Wall Materials Due to the Synergistic Effect of Helium and Hydrogen Isotopes," Journal of Nuclear Materials, 212-215, pp. 1390-1395.

[5] O’Donnel, I. J., Huthmann, H., Tavassoli, A. A., 1996, "The Fracture Toughness Behavior of Austenitic Steels and Weld Metal Including the Effects of Thermal Ageing and Irradiation," Int. J. Pres. Ves. \& Piping, 65, pp. 209-220.

[6] Kain, V., Chandra, K., Adhe, K.N., De, P.K., 2004, "Effect of Cold Work on LowTemperature Sensitization Behavior of Austenitic Stainless Steels," Journal of Nuclear Materials, 334, pp. 115-132.

[7] Hide, K., Onchi, T., Oyamada, R., Kayano, H., 1996, "Mechanical Response of Irradiated Thermally-Sensitized Type 304 Stainless Steels," Journal of Nuclear Materials, 232, pp. 3043.

[8] Guan, K., Xu, X., Xu, H., Wang, Z., 2005, "Effect of Aging at $700^{\circ} \mathrm{C}$ on Precipitation and Toughness of AISI 321 and AISI 347 Austenitic Stainless Steel Welds," Nuclear Engineering and Design, 235, pp. 2485-2494.

[9] Ilyin, A. M., 1998, "Some Features of Grain Boundary Segregation in Sensitized Austenitic Stainless Steel," Journal of Nuclear Materials, 252, pp. 168-170.

[10] ASTM E1820-99 "Standard Test Method for Measurement of Fracture Toughness", 1999 Annual Book of ASTM Standard Volume 3.01, American Society for Testing and Materials, 1999. 